\title{
Multifocal renal cell carcinoma in sibs from a chromosome 9 linked (TSC1) tuberous sclerosis family
}

Julian R Sampson, Anup Patel, A David Mee

\begin{abstract}
Multifocal renal cell carcinomas (RCCs), together with angiomyolipomas (AMLs) and renal cysts, were identified in early adult life in two sisters with tuberous sclerosis (TSC). They were members of a multigenerational tuberous sclerosis family showing strong evidence for a mutant TSC causing gene on chromosome 9 (TSC1). Previous reports of multifocal RCC in young patients with TSC suggest that constitutional mutations at the TSC loci may predispose to RCC. In the rat a germline mutation affecting the TSC2 gene is associated with transmission of multifocal RCC as an autosomal dominant trait. However, the cases reported here are the first to suggest a similar role for the TSC1 gene in renal cell carcinogenesis.
\end{abstract}

(f Med Genet 1995;32:848-850)

Tuberous sclerosis (TSC) is an autosomal dominant disorder associated with the development of a wide variety of hamartomatous lesions in many tissues and organs. ${ }^{1}$ The birth frequency has been estimated at 1 in $5800 .^{2}$ Two TSC causing genes have been localised to human chromosomes 9 (TSC1) ${ }^{3}$ and 16 (TSC 1$)^{4}$ but only the TSC 2 gene has been isolated. ${ }^{5}$ Loss of heterozygosity at $9 \mathrm{q} 34$ and $16 \mathrm{p} 13.3$ in TSC associated hamartomas indicate that both the TSC 1 and TSC2 genes act as tumour suppressor genes. ${ }^{67}$ In the kidneys, TSC is associated with the development of angiomyolipomas (AML), cysts, and much less frequently renal cell carcinomas (RCCs) with clear cell or oncocyte histology. ${ }^{1}$

Here we report the occurrence of multifocal RCC in two sisters in early adult life. In one sister the RCCs were bilateral and metachronous. Genetic linkage studies showed that TSC in the family could be attributed to a mutation at the TSC1 locus on chromosome $9^{8}$ (fig 1). These observations suggest a role for the TSC1 gene in the genesis of RCC, similar to that already reported for the TSC2 gene in an animal model, the Eker rat. ${ }^{910}$

\section{Case reports}

CASE 1

A 35 year old mother of three presented with right loin pain, dyspnoea on exertion, and a mass in the right flank. She had been diagnosed as having TSC eight years previously, when she and other members of her family were investigated following diagnosis of TSC in a cousin who developed epilepsy. Clinical and genetic investigation of her family (family 1013) has confirmed segregation of a tuberous sclerosis causing gene on chromosome 9 (the TSC1 gene) through her family for at least four generations $^{811}$ (fig 1).

Examination of case 1 at presentation confirmed adenoma sebaceum, subungual fibromata, shagreen patches, and multiple hypopigmented macules, confirming the diagnosis of TSC, and showed a tender $6-8 \mathrm{~cm}$ mass in the right flank. Renal ultrasound scan showed a large mass at the lower pole of the right kidney which appeared to compress the inferior vena cava and the aorta. The left kidney appeared normal. Renal CT scan showed multiple, small, low density lesions, consistent with angiomyolipomata, and a large solid mass at the right lower pole suggestive of renal cell carcinoma or a large angiomyolipoma. Isotope bone scan and chest $x$ ray were normal.

A radical right nephrectomy was performed. Pathological examination showed a $5 \mathrm{~cm}$ smooth lined lower pole cyst containing a $2 \mathrm{~cm}$ clear cell papillary renal adenocarcinoma involving part of the cyst wall, and a second smaller clear cell papillary adenocarcinoma was present some distance from the main tumour. Fibrovascular cores containing abundant smooth muscle and collections of smooth muscle fibres were present beneath the renal capsule. Four years later, the patient remains well and follow up CT scans have shown a stable $1.5 \mathrm{~cm}$ low density lesion in her remaining kidney, consistent with an angiomyolipoma.

\section{CASE 2}

The elder sister of case 1 also had manifestations of TSC (adenoma sebaceum, periungual fibromata, shagreen patches, and hypopigmented macules) and at 27 years of 


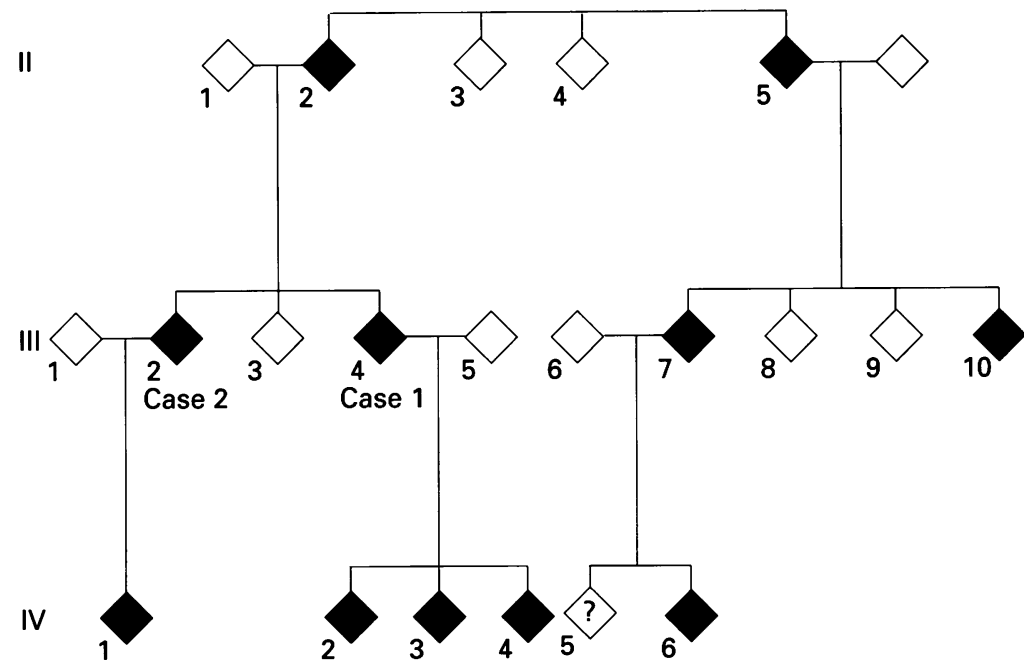

Figure 1 Pedigree of family 1013 with tuberous sclerosis. The sisters in whom renal cell carcinomas were diagnosed are indicated (case 1 and case 2). Previously reported linkage investigation has confirmed that the mutant TSC gene segregating in this family maps to chromosome region $9934 .^{8}$ The germline mutation is therefore of TSC1 type. Two point analysis versus a TSC1 linked dinucleotide repeat polymorphism in the arginosuccinate synthetase gene generated a lod score of 3.86 with no recombinant meioses. ${ }^{8}$ An affecteds only analysis yields a lod score of $2 \cdot 71$, while linkage to the TSC2 region has been excluded. ${ }^{11}$ Family member IV.5 had no symptoms of TSC, but was not included in the linkage analysis because age precluded consent to radiological investigation for asymptomatic evidence of TSC.

\section{Discussion}

In TSC, renal cysts, angiomyolipomas, and more rarely carcinoma may be found separately or may coexist, making evaluation difficult. Preoperative distinction between angiomyolipoma and renal cell carcinoma usually rests with imaging techniques such as sonography, computerised tomography, or magnetic resonance imaging, which identify a high fat content in angiomyolipoma. More subtle features including early arteriovenous shunting, anechoic rim or intratumoural cysts, ${ }^{12}$ or intralesional calcification may be suggestive of carcinoma. Particular difficulties in distinguishing carcinoma from AML arise when areas of haemorrhage or necrosis in a renal cell carcinoma give multiple echos which are a characteristic of angiomyolipoma, ${ }^{13}$ or when arteriovenous shunting through an AML with early filling of the renal vein is incorrectly taken to suggest the presence of renal cell carcinoma. ${ }^{14}$ In contrast, the presence of solid elements within a renal cyst (as seen in one of the sisters described here) is suspicious of malignancy, and in these circumstances positive aspiration cytology may yield a more definitive diagnosis.

There have been no systematic studies of renal cell carcinoma in TSC, although at least 21 case reports have been published (references available from authors on request). In an unselected series of 256 TSC patients, one of us (JS) noted only two further cases of recognised renal cell carcinoma. Although published cases are likely to be subject to reporting bias, it is noteworthy that, among these, presentation was at a mean age of only 23.3 years (range 7-39 years) and that nine of 21 cases were bilateral. These observations are consistent with the TSC genes predisposing to renal cell carcinoma through a two hit or analogous mechanism as first proposed for retinoblastoma by Knudson. ${ }^{15}$ The human TSC2 gene was recently isolated from chromosome 16 and has been shown to have the properties of a tumour suppressor gene, consistent with this hypothesis. ${ }^{57}$ Evidence that the TSC2 gene may be involved in renal cell carcinogenesis is provided by an animal model, the Eker rat. This strain carries an insertional mutation affecting the homologue of the human TSC2 gene $^{910}$ and develops multifocal RCC as a dominant trait. Histologically the tumour cells are oncocytelike, eosinophilic, basophilic, or mixed, but not of clear cell type. ${ }^{16}$ In contrast, the human TSC1 gene has not yet been isolated from chromosome 9 and no animal model for TSC 1 has been described. The cases reported here suggest that the TSC1 gene, as well as the TSC2 gene, can play a role in the genesis of RCC.

Although the first tumour occurring in case 2 of the present report showed penetration of the renal capsule, vascular invasion, and metastasis to regional lymph nodes, the patient has remained disease free for 15 years after complete surgical excision and radiotherapy. Some TSC patients with associated RCC have remained well on follow up, despite histological evidence for metastasis at presentation ${ }^{17} 18$ and

only three of 21 previously reported cases are angiomyolipomas. The patient remains free recurrence 15 years after the first RCCs were diagnosed and has now been successfully transplanted. 
known to have died of metastatic disease. ${ }^{19-21}$ Thus, RCC associated with TSC may have a better prognosis than sporadic RCC. RCCs reported in TSC patients have often been discovered coincidentally during investigation of other TSC associated renal pathology, particularly AML, and this might suggest survival advantage through early diagnosis in some cases. Similarly angiomyolipomatous involvement is more marked in females with TSC than in males ${ }^{22}$ and the chance detection of RCC during investigation of AML might underlie the female preponderance of RCC recognised in association with TSC (16 out of 21 cases). Despite these caveats, long term survival of TSC patients presenting symptomatically with apparently advanced disease suggests that TSC associated RCC may indeed be less aggressive than its sporadic counterpart.

Further studies are required to establish both the place of renal imaging in asymptomatic patients with TSC and the mechanisms through which TSC gene mutations are involved in renal cell carcinogenesis.

The authors wish to thank the Tuberous Sclerosis Association (GB) for support and the members of family 1013 for thei help with the investigations.

1 Gomez MR. Tuberous sclerosis. 2nd ed. New York: Raven Press, 1988.

2 Osborne JP, Fryer A, Webb D. Epidemiology of tuberous sclerosis. Ann NY Acad Sci 1991;615:125-7.

3 Fryer AE, Chalmers A, Connor JM, et al. Evidence that the gene for tuberous sclerosis is on chromosome 9. Lancet 1987; i: $659-61$.

4 Kandt RS, Haines JL, Smith M, et al. Linkage of an important gene locus for tuberous sclerosis to a chromosome 16 marker for polycystic kidney disease. Nature Genet 1992;2:27-41.

5 The European Chromosome 16 Tuberous Sclerosis Consortium. Identification and characterisation of the tuberous sclerosis gene on chromosome 16. Cell 1993;73: 1305-15.

6 Green AJ, Johnson PH, Yates JRW. The tuberous sclerosis gene on chromosome $9 \mathrm{q} 34$ acts as a growth suppressor.

Hum Mol Genet 1994;3:1833-4.
7 Green AJ, Smith M, Yates JRW. Loss of heterozygosity on chromosome $16 \mathrm{p} 13.3$ in hamartomas from tuberous sclerosis patients. Nature Genet 1994;6:193-6.

8 Nellist M, Brook-Carter PT, Connor JM, Kwiatkowski DJ, Johnson P, Sampson JR. Identification of markers flanking the tuberous sclerosis locus on chromosome 9 (TSC1). $\mathcal{J}$ Med Genet 1993;30:224-7.

9 Yeung RS, Ziao GH, Jin WC, Testa JR, Knudson AG. Predisposition to renal cell carcinoma in the Eker rat is determined by germ-line mutation of the tuberous sclerosis 2 (TSC2) gene. Proc Natl Acad Sci USA 1994;91:1141316.

10 Kobayashi T, Hirayama Y, Kobayashi E, Kubo Y, Hino O. A germline insertion in the tuberous sclerosis (TSC2) gene gives rise to the Eker rat model of dominantly inherited cancer. Nature Genet 1995;9:70-4.

11 Janssen B, Sampson J, van der Est M, et al. Refined localization of TSC 1 by combined analysis of $9 \mathrm{q} 34$ and $16 \mathrm{p} 13$ data in 14 tuberous sclerosis families. Hum Genet 1994; 94:437-40.

12 Yamashita $Y$, Ueno S, Makita O, et al. Hyperchoic renal tumours: anechoic rim and intratumoral cysts in ultrasound differentation of renal cell carcinoma from angiomyolipoma. Radiology 1993;188:179-82.

13 Takeyama M, Arima M, Sagawa S, Sonoda T. Preoperative diagnosis of coincident renal cell carcinoma and renal angiomyolipoma in non-tuberous sclerosis. $\mathcal{F}$ Urol 1982 128:579-81.

14 Danneels F, Meeus L, Casselman JW, et al. Giant angiomyolipoma with typical arteriovenous shunting: CT and angiographic studies. 7 Belge Radiol 1990;73:135-7.

15 Knudson AG. Mutation and cancer: statistical study of retinoblastoma. Proo Natl Acad Sci USA 1971;68:820-3.

16 Everitt JI, Goldsworthy TL, Wolf DC, Walker CL. Hereditary renal cell carcinoma in the Eker rat: a rodent editary renal cell carcinoma in the Eker rat: a rode
familial cancer syndrome. $\mathcal{O}$ Urol 1992;148:1932-6.

17 Weinblatt ME, Kahn E, Kochen J. Renal cell carcinoma in patients with tuberous sclerosis. Pediatrics 1987;80: 898-903.

18 Taylor RS, Joseph DB, Kohaut EC, Wilson ER, Bueshen AJ. Renal angiomyolipoma associated with lymph node involvement and renal cell carcinoma in patients with tuberous sclerosis. F Urol 1989;141:930-2.

19 Gutierrez O, Burgener FA, Schwartz S. Coincident renal cell carcinoma and renal angiomyolipoma in tuberous sclerosis. $A \mathscr{R}$ 1979;132:848-50.

20 Takeuchi S, Gotoh S, Tari K. A case of rental cell carcinoma in tuberous sclerosis followed by basic AFP - a new
carcinoembryonic protein. Hinyokika Kiyo 1984;30:6718.

21 Ahuja S, Loffler W, Wegener OH, Ernst H. Tuberous sclerosis with angiomyolipoma and metastasised hy-
pernephroma. Urology 1986;28:413-19.

22 van Baal JG, Fleury $P$, Brummelkamp $H$. Tuberous sclerosis and the relation with renal angiomyolipoma. A genetic and the relation with renal angiomyolipoma. A genetic
study on the clinical aspects. Clin Genet 1989;35:167-73. 